Citation: : Grant M, Radford K, Sinclair E, Walker M (2014) Return to work after stroke: recording, measuring, and describing occupational therapy intervention. British Journal of Occupational Therapy, 77(9), 457-465.

\title{
Return to work after stroke: recording, measuring, and describing occupational, therapy intervention
}

\author{
Mary Grant ${ }^{1}$, Kathryn Radford ${ }^{2}$ Emma Sinclair $^{3}$ and Marion Walker ${ }^{4}$
}

\author{
${ }^{1}$ Postgraduate Student, University of Nottingham, Division of Rehabilitation and Ageing, \\ Nottingham, UK \\ ${ }^{2}$ Associate Professor in Rehabilitation Research (Long-Term Conditions), University of \\ Nottingham, Division of Rehabilitation and Ageing, Nottingham, UK \\ ${ }^{3}$ Assistant Psychologist, University of Nottingham, Division of Rehabilitation and Ageing, \\ Nottingham, UK \\ ${ }^{4}$ Professor in Stroke Rehabilitation, University of Nottingham, Division of Rehabilitation and \\ Ageing, Nottingham, UK
}

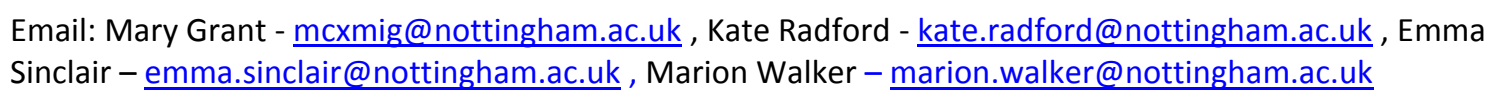

\section{$\underline{\text { ABSTRACT }}$}

Introduction:

Existing research on vocational rehabilitation following stroke has been criticised for not describing intervention in sufficient detail for replication or clinical implementation. The purpose of this study was to test the feasibility of recording and measuring the content of an early stroke-specific vocational rehabilitation intervention delivered to participants in a feasibility randomized controlled trial, using a proforma previously developed for a study of vocational rehabilitation following traumatic brain injury.

Method:

The proforma was adapted for use in stroke with input from an expert panel and was used to record intervention content, in 10-minute units, following each intervention session.

Findings:

Twenty-five people, working or in education at the time of stroke, participated in the study. Two thirds of the therapists' time was spent in face-to-face contact (43\%) and liaison with the patient and others (20\%). Intervention mainly focused on work preparation (21\%) and the return to work process (24\%). The remaining time was consumed by administration (19\%) and travel (18\%).

Conclusion:

The proforma was quick and easy to use and captured the main focus of intervention. This study suggests that it can be used to record stroke-specific vocational rehabilitation intervention content and has potential for wider use in research and clinical practice. 
Every year, some 152,000 people in the United Kingdom (UK) suffer a stroke (Stroke Association 2012), a quarter of whom are of working age (Daniel et al 2009), yet fewer than $50 \%$ of those working at stroke onset return to work. For many, a primary goal is to regain financial independence and return to work, yet residual physical, visual, cognitive, and language deficits may limit a person's ability to return to a previous job and present obstacles to finding a new one (Doucet et al 2012, Saeki and Toyonaga 2010, Vestling et al 2003). People who cannot return to work or re-train may face a lifetime of state dependence. Affording those who have the capacity to work the opportunity to do so is a UK Government priority (Department for Work and Pensions [DWP] 2012, DWP 2004, DWP et al 2005). Providing the support necessary to enable people who develop a health condition to return to work is recognized both as a role for healthcare professionals (Black 2008, Black and Frost 2011) and a health outcome (Department of Health [DH] 2010). This sort of support is known as vocational rehabilitation (VR). VR is defined as a process whereby those disadvantaged by illness or disability can 'access, maintain or return to employment' (Tyerman and Meehan 2004). It is 'Quality requirement 6 ' of the National service framework: long-term neurological conditions (DH 2005), which states that 'People with long-term neurological conditions should have access to appropriate vocational assessment, rehabilitation and on-going support, to enable them to find, regain or remain in work and access other occupational and educational opportunities (DH 2005).'

However, VR services for stroke survivors in the UK are patchily provided and meet less than $10 \%$ of the estimated requirement (Deshpande and Turner-Stokes 2004, Playford et al 2011). Only 37\% of National Health Service (NHS) primary care trusts (PCTs) offer stroke rehabilitation that addresses work needs (Care Quality Commission [CQC] 2011).

Defining and specifying rehabilitation interventions for research purposes is one of the most neglected areas in rehabilitation research (Hart 2009, Whyte and Hart 2003). Not only is it important clinically (for example, when attempting to implement research findings in practice) and for informing health policy and clinical guidelines, it is also important for planning and securing funding for further research (Wade 2003): for example, when repeating studies in different regions or countries, when moving from feasibility studies to definitive trials, for describing intervention components and the difference between the active intervention and usual care, and when checking the fidelity of an intervention as part of a trial or for making sense of positive or negative outcomes.

Unlike pharmacologic interventions, whose active ingredients can be identified and defined by dose, route, and administration instructions, VR interventions are complex. They consist of theories, and processes that interact and are rarely linear (Hart 2009, Medical Research Council [MRC] 2008), and involve the actions of several people. They are often individually tailored and occur as part of complex systems (health and social care, employment, and education) that are prone to modification. They may be influenced by many potential 'confounders' other than the intervention in question: for example, by environmental factors (such as where the intervention takes place and access barriers - for instance, transport), treatment intensity, the therapist's expertise, whether and how feedback is given, and both 'therapist' and 'patient' factors such as personality, warmth, and communication skills, how the patient engages with the therapist and/or process, motivation, and effort (Sherer et al 2007).

Difficulty in describing and prescribing complex rehabilitation interventions has resulted in research targeted at the system or process level, for example 'stroke unit care' or 'community rehabilitation', where individual components and causal relationships remain indistinguishable. As a result, rehabilitation has been termed a black box, whose contents and active ingredients remain unclear (Wade 2001). Whilst process level research is helpful for identifying what works overall, it may be less useful for identifying what works for whom (Hart 2009, Whyte and Hart 2003) and in what context (Wade 2005), and which components are ineffective and could therefore be excluded. It is also less helpful in theory generation and in defining protocol-based treatments that can be 
implemented in clinical practice (Whyte and Hart 2003). A failure to describe interventions also reduces the credibility of rehabilitation in a competitive healthcare market (Wade 2005) and limits research funding opportunities.

As one in a series of Collaboration for Leadership in Applied Health Research and Care Nottinghamshire, Derbyshire, and Lincolnshire studies (CLAHRC-NDL, see CLAHRC-NDL 2013 for an archived description of the project) exploring the local context for health-based service developments to support post-stroke rehabilitation, we developed an early stroke-specific occupational therapy vocational rehabilitation intervention for supporting stroke survivors back into work (Grant et al 2012) and tested the feasibility of delivering and measuring its effects and costs in a feasibility randomized controlled trial (RCT).

The early stroke specific VR (ESSVR) was based on a set of best practice guidelines for VR in people with acquired brain injury (ABI) (Tyerman and Meehan 2004), and evidence supporting the need for a case coordination model in ABI VR (Fadyl and McPherson 2009, Hart et al 2006). It included assessment of the individual, job analysis, provision of information, education, advice and psychological support, goal setting, work site assessment, liaison (with other services, professionals, the family and employer where appropriate), and meetings to prepare and plan for a return to work. Work preparation included simulated or relevant activities and interventions tailored to individual needs (for example, fatigue management, cognitive rehabilitation). The return to work was monitored and graded with participants, employers, and others involved in supporting the return (for example, disability employment adviser [DEA] and family members, where appropriate) and modifications were made as needed. Ongoing support was provided, leading to a gradual withdrawal and discharge.

AIM

The purpose of this study was to test the feasibility of capturing the content of a stroke-specific VR intervention using a proforma developed for measuring the content of an early traumatic brain injury (TBI) specialist occupational therapist VR intervention (Phillips et al 2010).

\section{METHOD}

As part of a feasibility RCT, comparing ESSVR, delivered by an occupational therapist, to usual care, the content of the VR intervention was recorded for participants randomized to receive ESSVR. A proforma developed in Excel for recording VR in people with TBI (Phillips et al 2010), and used in a study comparing early specialist TBI VR (ESTVR) to usual care (Radford et al 2013) was adapted with the help of an expert panel of VR service providers (specializing in stroke and vocational rehabilitation) and service users for use following stroke; expert opinion, as well as evidence from the stroke literature, were drawn on to suggest changes necessary for its use with stroke survivors. The existing guidelines for using the proforma were also adapted for use with stroke.

The original TBI proforma included fifteen intervention categories, based on the British Society of Rehabilitation Medicine's best practice recommendations for VR in people with an ABI (Tyerman and Meehan 2004), with intervention recorded in units of 10 minutes. The proforma, as adapted for stroke, included 16 categories (Appendix 1). Nine additional subcategories were included to encompass problems specific to stroke that did not feature in the VR intervention following TBI. These were pain management, visual problems, upper limb work, sensory problems and communication/ speech (under the 'physical' interventions category), adjustment and re-evaluation (under 'dealing with psychological issues') (Radford and Walker 2008), and work site visit (under 'return to work process'). It was also thought that specific liaison would be more likely to take place with physiotherapy and speech and language therapy following stroke, therefore these subcategories were added under 'liaison'. 


\section{Participants}

Participants were people with stroke who had met the inclusion criteria and consented to participate in a case study pilot and a feasibility trial comparing an ESSVR intervention to usual care.

Inclusion criteria:

- admitted to stroke unit in one English county following diagnosis of stroke

- 16 years of age and over

- working at stroke onset in paid or voluntary work or education

- intending to return to work or education

People who were not intending to return to work/ education, had a medical reason precluding work (for instance, uncontrolled epilepsy), who refused consent, or who were unable to consent for themselves were excluded. Ethical approval for the study was obtained.

\section{Recruitment and intervention}

Participants were recruited whilst in hospital, or at home shortly following discharge. Informed consent was obtained by the research occupational therapist (MG - first author) or a research assistant. Intervention commenced immediately for those randomized to receive ESSVR.

\section{The use of the proforma}

The proforma was tested on two case study participants (without further amendment), before being used to record the intervention delivered to trial participants randomized to receive the ESSVR intervention.

Intervention was recorded in 10-minute units following each intervention session by the treating occupational therapist, who ticked any categories on paper copies of the proforma that corresponded directly to the intervention delivered during that session. These proformas were stored securely with therapy records.

\section{Data analysis}

Data from the completed paper copies of the proformas were then entered into an Excel spreadsheet for analysis. Descriptive analysis of the overall time spent on face-to-face, liaison, administration, and travel was calculated and, in addition, the breakdown of specific components of intervention and liaison were analysed. Delivery of intervention was explored by looking at the date intervention commenced, its duration, number of sessions, and location. Demographic data about the participants were analysed using SPSS (version 17) statistical software.

\section{FINDINGS}

\section{Participants}

Proformas were completed for two case study participants and 23 trial participants. Demographic details of participants are summarized in Table 1. All participants were white British, most had suffered a minor or moderate stroke, and $84 \%$ were in semi-professional or professional/managerial jobs at stroke onset. Seventeen were in full-time work, six in part-time work and one was combining full-time education with part-time work at stroke onset. One had not worked for a year before his stroke, but told research staff that he was working at the time of recruitment. Eight of those working full time were self employed and four out of the six who were part time were engaged in voluntary work. 
Intervention sessions took approximately 5 minutes to record each time the proforma was completed.

A number of modifications were made to allow usage of the proforma in the present study. One descriptor needed amendment: 'walking outside the home' in the 'mobility' section was changed to 'walking', as some participants were working on indoor mobility. The 'meetings' subcategories of the 'return to work process' section were used to record both formal meetings with employers and also sessions with participants when employers were not involved.

Some subcategories were not used in the current study: these were, 'splinting' in the 'physical' section, as no splints were required by participants; 'toileting' in the 'personal activities of daily living' section; 'money/budgeting', 'correspondence', and 'managing appointments' in the instrumental activities of daily living section; 'motivation' from the 'dealing with psychological issues' section; 'work assessment meeting' in the 'return to work process' section; 'case manager', 'CBT', and 'work provider' in the 'liaison' section; and 'information about the rehabilitation process' and 'advice/support regarding work assessment' in 'OT activity with employer' section.

There were some difficulties with the proforma that need to be considered for future use. Some categories appeared to overlap: for example, 'discussion of work options' under the 'work preparation' heading and 'return to work planning meetings' in the 'return to work process' section. Some discussion of work options took place in these meetings, but if these were discussed more informally with the participant in their own home at an earlier stage, then this was recorded under 'discussion of work options'. 'OT activity with employer' also overlapped with 'return to work planning meetings' and 'monitoring/grading meetings', as most activity was an integral part of these meetings. 'General education re stroke and/or RTW' was sometimes inextricably linked with 'work preparation' subcategory 'discussing work options', and with 'family/carer support'. 'Education re cognitive skills' and 'other' category of 'instrumental activities of daily living' (for instance, use of computer/laptop) could also be seen as work preparation, but the practical aspects of work preparation are more specifically broken down under other headings. Confidence building can be achieved by doing specific tasks and practical activities and also through feedback given at monitoring, grading, and maintenance meetings, so this was another area of overlap.

In addition, it would have been useful to have 'other OT' as a category in the 'liaison' section, as liaison with other outpatient and community occupational therapists was recorded under 'other' and had to be separated out later in order to look at overall liaison with health professionals.

\section{Delivery of intervention}

\section{Timing and duration of intervention}

Intervention commenced between 10-53 (mean 30, SD 12) days post stroke. Participants received a mean of 10 (SD 7, range 1-25) intervention sessions and an average session lasted approximately 1 hour. These data are broken down according to stroke severity in Table 2. For participants where the National Institutes of Health Stroke Scale (NIHSS) score was missing from the medical notes, the Stroke Impact Scale score was used as an alternative method of classifying stroke severity.

\section{Location of intervention}

Almost two thirds of sessions took place in participants' homes (64\%), $28 \%$ in the workplace, and $1 \%$ in Job Centres. Other locations (7\%) included the stroke rehabilitation ward prior to discharge (46\%), the meeting room of a dis - ability rights charity $(13 \%)$, and a voluntary organization jobs brokerage centre (7\%). 
Two thirds of occupational therapists' time was spent delivering the intervention itself (43\% face-toface contact and $20 \%$ liaison with the participant and others) and the other third was split almost equally between administration (19\%) (writing notes and reports) and travelling (18\%) to see participants at home or their work places.

\section{Describing the content of intervention}

The content of intervention is summarized in Fig. 1. The greatest proportion of time was spent on preparing participants for work (18\%) and the return to work process (24\%).

Work preparation (18\%)

The majority of the time dedicated to work preparation was spent discussing work options (60\%): for example, asking participants about their ideas concerning the timing of the return to work and the hours they felt able to manage. This preparation for planning the return to work prior to discussions with the employer also involved discussing how to phase back into their role and responsibilities at work.

Teaching pacing and fatigue management was the second most common activity $(27 \%)$ used in preparing someone for returning to work. However, this also formed part of later intervention: for example, when it might be addressed when reviewing return to work because sometimes it was only when people had returned to work that they realized the impact of fatigue and the challenge of pacing themselves.

Other aspects of work preparation (7\%) included applying for voluntary work, filling in Criminal Record Bureau check forms, visits to Job Centre Plus, and looking for education and retraining opportunities (for example, courses). The remaining $6 \%$ of time was spent focusing on the use of routines and timekeeping, patient contact with workplace, detailed job analysis, and identifying potential problems and solutions.

Return to work process (24\%)

The return to work process mainly comprised of meetings focused on return to work planning (13\%), monitoring and grading (65\%), and maintenance (10\%). Sometimes these meetings were with the employer and other times they were only with the participant depending on the individual work situation. Monitoring and grading meetings took place once the person had returned to work, and involved reviewing the return to work plan and making modifications if necessary.

These modifications included making changes to days or hours of work or duties being undertaken. Maintenance meetings occurred after the person had returned to their previous hours and duties to ensure work return was sustained and any difficulties which arose could be resolved. The remaining $12 \%$ of time was taken up with work site visits (providing advice, education, and written information to employers) and covering statutory issues.

Current issues (16\%)

One of the predominant current issues was medical (32\%): for example, discussing the side effects of medication being taken to prevent future strokes or for managing diabetes. The other prevalent focus was on current work issues (31\%), which involved matters which had arisen since the previous meeting in the work place: for example, conversations the employee had had with their line manager or current concerns about work. The third greatest proportion (15\%) was spent on 'other issues' such as accomodation, financial difficulties, or dicussing input from other people. The remaining $22 \%$ of time was spent on social, family, and benefit payments issues. 
Just over half the time spent dealing with psychological issues was focused on the adjustment and re-evaluation process $(51 \%)$. Low mood (18\%) and anxiety (10\%) were prevalent issues. This involved providing informal psychological support, which included listening to the participant, providing information, and suggesting strategies for coping and adjustment. Two participants were referred to the stroke coordination and support service for additional psychological support, due to low mood. The remaining $21 \%$ of time was spent on confidence building, behavioural problems, dealing with others, and teaching relaxation techniques.

\section{Mobility (7\%)}

Walking activities (in and outside the home) (33\%) and provision of information and advice about driving (33\%) were the most frequently completed categories in this section. The latter included providing information about Driving and Vehicle Licensing Agency (DVLA) procedures and details of a local specialist driving and mobility centre. The rest of the time (34\%) was spent focusing on road safety $(2 \%)$, using public transport $(9 \%)$, route finding $(2 \%)$, and other mobility issues $(21 \%)$ that included working on standing balance, advice about exercise to increase fitness and stamina and reduce risk of further stroke, and assisting with an application to a charity for a mobility scooter.

\section{Cognitive and executive skills (4\%)}

The prime focus of this area of intervention was education about cognitive and executive skills (66\%) and included activities involving planning and multitasking. Memory strategies were taught to some participants (14\%), and standardized tests (13\%) were carried out when appropriate: for example, the Rivermead Behavioural Memory Test (RBMT-3) or the Behavioural Assessment of the Dysexecutive Syndrome (BADS).

This guided intervention and strategies were developed collaboratively for coping with cognitive difficulties in the workplace. Referrals were also made to a clinical neuropsychologist for two participants who required in-depth cognitive assessment; both were subsequently referred on to the local outpatient neurorehabilitaion service for a memory group intervention facilitated by an occupational therapist.

Liaison

Most liaison (Fig. 2) took place between the therapist and the participant (46\%), by phone, email, and text messaging. Liaison with health professionals (20\%) included general practitioners, consultant, psychologist, physiotherapists, speech and language therapists, and other occupational therapists involved with the participants' care from intermediate care, early supported discharge, and outpatient therapy services. In this case, liaison was by letter, phone, and email, and occasionally face to face.

Voluntary organizations included those brokering voluntary jobs and a charity offering leisure activities to stroke survivors and legal advice regarding return to work.

The stroke support and coordination service, led by an occupational therapist in the south and a nurse in the north of the county concerned, is jointly funded by health and social care. Stroke survivors and their families are seen by stroke support workers, who offer advice and information about benefits and local services, and provide psychological support during the process of adaptation following stroke.

Liaison with the employer, human resources, and occupational health involved attendance at meetings or appointments in an advocacy role. Letters summarizing these meetings were sent to the participant and copied to general practitioners and those in attendance. Direct contact only took place with the employers of seven participants. Eight participants were self employed and four were 
engaged in voluntary work. Four of the remaining six participants did not want the occupational therapist to have direct contact with their workplace, although three of these acted as a conduit of information; passing on leaflets, booklets, and letters with recommendations from the therapist to their employer.

The other two participants did not have an employer for the occupational therapist to liaise with since one had been made redundant just prior to the stroke and the other lost his job just after the stroke.

\section{DISCUSSION}

In this study we have described the rehabilitation intervention in full, as recommended by previous researchers (Hart 2009, Wade 2005, Whyte and Hart 2003). A proforma, previously developed for use in a study of VR following TBI (Phillips et al 2010), was adapted for stroke and used as part of a feasibility RCT, to record and categorize the content of stroke-specific vocational rehabilitation.

The proforma was quick and easy to complete and enabled the intervention delivered to be described. The transfer of information from paper copies to an Excel spreadsheet facilitated data analysis and was deemed to be a feasible method suited to both clinical practice and research. A spreadsheet format offers the opportunity for the proforma to be adapted for completion online or using mobile technology such as smartphones or tablet computers for future use.

The proforma was able to capture the main focus of intervention, but there were areas of overlap. The practical challenge of recording the multi-tasking that takes place during intervention sessions was also faced by Phillips et al (2010) when categorizing VR occupational therapy following TBI and highlights the problem of describing an intervention that is both complex and multifaceted. In both studies the occupational therapists recorded the main focus of intervention, but this may have resulted in some areas of intervention (for example, confidence building and motivation) being under-represented in the results because they were being worked on through the practical activities or meetings that were recorded as the main focus of the session.

Two therapists, one in the previous TBI study (Phillips et al 2010) and one in the current stroke study, were able to use the proforma in a similar way; however, inter-rater reliability would need to be investigated in future studies. The greatest proportion of time was spent on work preparation and the return to work process in both studies. However, more time was spent on assessment by Phillips. In this stroke study, baseline data gathered from participants in the feasibility trial were used to inform the assessment by the VR occupational therapist (VROT), but a proforma was not completed for the time spent on the baseline data collection session, since it was not always carried out by the VROT. To ensure consistency, decisions on which sessions are recorded need to be considered in future research.

The proforma was able to distinguish between the intervention provided to different client groups. For example, participants in the TBI study appeared to have fewer physical difficulties, whereas in this stroke study a number of people had physical limitations and needed intervention focused on mobility and driving. In this study the VR occupational therapist also offered support to family members as part of the intervention, which in the TBI study was delivered predominantly by TBI case managers.

Although there was consensus among the expert panel that the key areas of intervention were included and the proforma was appropriate for use following stroke, it did not distinguish between practical intervention and monitoring progress under the same headings (as an example, there would be no distinction between a session where the VR occupational therapist practised travelling on a bus with a patient and one where a therapist talked to the patient about how they are 
managing public transport). However, distinguishing between these two levels of intervention would make the proforma unwieldy and impractical to use.

Direct employer contact was only recorded in a limited number of cases; this could be explained, in part, by job type, given that eight participants were self employed and four were volunteers, and therefore had no employer. Four participants were offered the opportunity for direct employer contact with the therapist but preferred to manage this aspect of their return to work independently. Possible reasons for this could be a reluctance to disclose or highlight the impact of stroke due to fear of losing their job. Best practice guidelines for vocational rehabilitation (Tyerman and Meehan 2004) recommend employer liaison, and previous research studies have cited employer attitudes, knowledge, and flexibility as important influences on the success of returning to work after a stroke (Alaszewski et al 2007, Coole et al 2013, Lock et al 2005). Similarly, only 6 out of 21 participants in the Phillips et al (2010) study on VR following brain injury received intervention directly involving the employer; however, the reasons for this may differ from those in the present study. The reasons why stroke survivors may or may not want rehabilitation therapists to liaise with their employer do not appear to have been investigated to date.

The usefulness of previous systematic reviews of the evidence for returning to work after stroke (Baldwin and Brusco 2011, Treger et al 2007) has been thwarted by poorly described research, lack of methodological detail, and a lack of evidence about which vocational rehabilitation interventions are effective following stroke. This study has recorded and described the content of a VR intervention delivered as part of a feasibility trial as a first step towards the identification of active ingredients for a successful return to work. The next step is to look at the relationship between interventions and vocational outcomes.

\section{Recommendations and future use of the}

\section{proforma}

The proforma can be used as a clinical tool in its current form but, as demonstrated above, the use of some subcategories will be open to interpretation. Further research is needed to refine and develop the proforma for use in research studies, in order to enable detailed description and evaluation of this complex intervention (MRC 2008). This could start with removing redundant subcategories (for instance, splinting). There also needs to be greater consensus on terminology used and clearer definitions and guidelines to improve consistency and clarity. For example, 'return to work planning meeting' should be differentiated from 'return to work planning discussion', with the former referring to a formal meeting with employer and the latter describing an informal dialogue about return to work with participant at home, or they could be recorded separately. The terms 'monitoring' and 'grading' could be replaced with 'reviewing' or 'managing return to work' to increase utility among a broader range of professionals. Inter-rater reliability testing would then be needed to assess the consistency of the refined proforma.

The proforma could also be used to collect information on work outcomes and has the potential to be adapted for use with a wide range of health conditions (for example, musculoskeletal and mental health) since many core components are generic to VR.

Limitations and strengths of the study

The proforma was used by one occupational therapist working as part of a funded research project seeing 25 stroke survivors in a feasibility RCT. This specialist intervention may differ from VR services that are embedded in broader programmes of neurological rehabilitation follow-ing stroke. However, the way the proforma was adapted, using the consensus of an expert panel to include broad headings and subheadings intended to embrace the full spectrum of components anticipated 
in a post stroke VR intervention, suggests it should capture the features of most VR interventions. Further research is now needed to evaluate whether it can.

Other limitations are outlined within the context of the discussion above, alongside recommendations for future study and improvement.

\section{CONCLUSION}

This study has shown that it is feasible for a proforma to be used to record occupational therapy VR intervention following stroke. It can be used in its current form in clinical practice and with further refinement it can be used in future research studies to describe, in detail, the intervention provided to support people with stroke to return to work. Such a tool would enable researchers to define the active ingredients or components of vocational rehabilitation for this group in future evaluation studies.

\section{Key findings}

- A proforma, developed to describe, record, and measure stroke-specific vocational rehabilitation in this study, has potential with further refinement for broader use in future research studies and clinical practice.

\section{What the study has added}

- The proforma developed facilitated the description of occupational therapy intervention for stroke survivors returning to work, enabling comparison with other vocational rehabilitation services and research studies.

\section{Acknowledgements}

The authors would like to thank the members of the expert panel for their contribution to the development of the proforma, and especially Julie Phillips and Jane Terry.

Conflict of interest: None declared.

Funding: The study was funded by National Institute of Health Research - Collaborative Leadership in Health Research and Care - Nottinghamshire, Derbyshire and Lincolnshire. It is also part of the first author's PhD study, funded by the Elizabeth Casson Trust through the United Kingdom Occupational Therapy Research Foundation. The funders had no other part in the direction of the study.

Research ethics: Ethical approval was obtained from Leicester, Northampton and Rutland Research Ethics Committee (REC reference: 10/H0406/21).

\section{References}

Alaszewski A, Alaszewski H, Potter J, Penhale B (2007) Working after stroke: survivors' experiences and perceptions of barriers to and facilitators of the return to paid employment. Disability and Rehabilitation, 29(24), 1858-1869.

Baldwin C, Brusco NK (2011) The effect of vocational rehabilitation on return-to-work rates post stroke: a systematic review. Topics in Stroke Rehabilitation, 18(5), 562-572.

Black C (2008) Working for a healthier tomorrow. London: TSO.

Black C, Frost D (2011) Health at work: an independent review of sickness absence in Great Britain. London: TSO. 
Care Quality Commission (2011) Supporting life after stroke: a review of services for people who have had a stroke and their carers. London: CQC.

CLAHRC-NDL (2013) Stroke rehabilitation research. Available at: http://www. clahrc-

ndl.nihr.ac.uk/clahrc-ndl-nihr/research/stroke-rehabilitation/index.aspx Accessed 20.03.13.

Coole C, Radford K, Grant M, Terry J (2013) Returning to work after stroke: perspectives of employer stakeholders, a qualitative study. Journal of Occupational Rehabilitation, 23(3), 406-418.

Daniel K, Wolfe CD, Busch MA, McKevitt C (2009) What are the social consequences of stroke in working-aged adults? A systematic review. Stroke, 40(6), 431-440.

Department of Health (2010) The NHS outcomes framework 2011/12. London: DH. Department of Health (2005) National service framework for long term conditions. London: DH.

Department for Work and Pensions (2012) Disability employment support: fulfilling potential. London: TSO.

Department for Work and Pensions (2004) Building capacity for work: a UK framework for vocational rehabilitation. London: DWP.

Department for Work and Pensions, Department of Health, Health and Safety Executive (2005) Health, work and wellbeing: caring for our future. London: DWP.

Deshpande P, Turner-Stokes $L$ (2004) Survey of vocational rehabilitation services available to people with acquired brain injury in the UK. In: A Tyerman, MJ Meehan, eds. Vocational assessment and rehabilitation after acquired brain injury: inter-agency guidelines. London: RCP.

Doucet T, Muller F, Verdun-Esquer C, Debelleix X, Brochard P (2012) Returning to work after a stroke: a retrospective study at the Physical and Rehabilitation Center 'La Tour de Gassies.' Annals of Physical Rehabilitation Medicine, 55(12), 112-127.

Fadyl JK, McPherson KM (2009) Approaches to vocational rehabilitation after traumatic brain injury: a review of the evidence. Journal of Head Trauma Rehabilitation, 24(3), 195-212.

Grant M, Sinclair E, Walker MF, Radford KA (2012) Vocational rehabilitation following stroke: describing intervention. International Journal of Stroke, 7(Suppl 2), 29.

Hart T (2009) Treatment definition in complex rehabilitation interventions. Neuropsychological Rehabilitation, 19(6), 824840.

Hart T, Dijkers M, Fraser R, Cicerone K, Bogner JA, Whyte J, Malec J, Waldron B (2006) Vocational services for traumatic brain injury: treatment definition, diversity within model systems of care. Journal of Head Trauma Rehabilitation, 21(6), 467-482.

Lock S, Jordan L, Bryan K, Maxim J (2005) Work after stroke: focusing on barriers and enablers. Disability and Society, 20(1), 33-47.

Medical Research Council (2008) Developing and evaluating complex interventions: new guidance. London: MRC.

Office for National Statistics (2000) Standard Occupational Classification 2000. Available at: http://www.ons.gov.uk/ons/guide-method/classifications/ archived-standardclassifications/standard-occupational-classification-2000/index.html Accessed 14.08.14. 
Phillips J, Drummond A, Radford K, Tyerman A (2010) Return to work after traumatic brain injury: recording, measuring and describing occupational therapy intervention. British Journal of Occupational Therapy, 73(9), 422-430.

Playford ED, Radford K, Burton C, Gibson A, Jellie B, Sweetland J, Watkins C (2011) Mapping vocational rehabilitation services for people with long term neurological conditions: summary report. London: DH. Available at: http://www.Itnc.org.uk/Research\%20pages/mapping_vocational_ rehab.html Accessed 10.12.12

Radford KA, Phillips J, Drummond A, Sach T, Walker M, Tyerman A, Haboubi N, Jones T (2013) Return to work after traumatic brain injury: cohort comparison and economic evaluation. Brain Injury, 27(5), 507-520.

Radford KA, Walker MF (2008) Impact of stroke on return to work. Brain Impairment, 9(2), 161-169.

Saeki S, Toyonaga T (2010) Determinants of early return to work after first stroke in Japan. Journal of Rehabilitation Medicine, 42(3), 254-258.

Sherer M, Evans CC, Leverenz J, Stouter J, Irby JW Jr, Lee JE, Yablon SA (2007) Therapeutic alliance in post-acute brain injury rehabilitation: predictors of strength of alliance and impact of alliance on outcome. Brain Injury, 21(7), 663-672.

The Stroke Association (2012) What is a stroke? Available at: http://www. stroke.org.uk/factsheet/what-is-a-stroke Accessed 15.08.14.

Treger I, Shames J, Giaquinto S, Ring H (2007) Return to work in stroke patients. Disability and Rehabilitation, 29(17), 1397-1403.

Tyerman A, Meehan MJ (2004) Vocational assessment and rehabilitation after acquired brain injury: inter-agency guidelines. London: RCP.

Vestling M, Tufvesson B, Iwarsson S (2003) Indicators for return to work after stroke and the importance of work for subjective well-being and life satisfaction. Journal of Rehabilitation Medicine, 35(3), 127-131.

Wade DT (2005) Describing rehabilitation interventions. Clinical Rehabilitation, 19(8), 811-818.

Wade DT (2003) Barriers to rehabilitation research, and overcoming them. Clinical Rehabilitation, $17(1), 1-4$.

Wade DT (2001) Research into the black box of rehabilitation: the risks of a Type III error. Clinical Rehabilitation, 15(1), 1-4.

Whyte J, Hart T (2003) It's more than a black box; it's a Russsian doll: defining rehabilitation treatments. American Journal of Physical Medicine and Rehabilitation, 82(8), 639-652 
Table 1. Demographic details of participants

\begin{tabular}{lr}
\hline Characteristic & $\mathrm{n}(\%)$ \\
\hline Numbers & 25 \\
Men & $18(72 \%)$ \\
Women & $7(28 \%)$
\end{tabular}

Age in years

Mean

Range

Ethnicity

British

Bamford classification

$\begin{array}{lrr}\text { PACS } & 5 & (20 \%) \\ \text { LACS } & 7 & (28 \%) \\ \text { TACS } & 3 & (12 \%) \\ \text { POCS } & 7 & (28 \%) \\ \text { Missing } & 3 & (12 \%) \\ \text { NIHSS } & & \\ \text { Minor (1-4) } & & \\ \text { Moderate (5-15) } & 10 & (40 \%) \\ \text { Moderate/severe (15-24) } & 7 & (28 \%) \\ \text { Severe (> 25) } & 2 & (8 \%) \\ \text { Missing } & 0 & (0 \%) \\ & 6 & (24 \%)\end{array}$

Stroke Impact Scale

$>65$

$19(76 \%)$

$50-65$

$4(16 \%)$

$<50$

$2(8 \%)$

Job category ${ }^{\star}$

1. Unskilled

$2(8 \%)$

2. Semi-skilled

3. Semi-professional

$11(44 \%)$

4. Professional

$10(40 \%)$

Marital status

Married

$17(68 \%)$

Single

$4(16 \%)$

Divorced

$2(8 \%)$

Living with partner

$2(8 \%)$

Length of stay in hospital (days)

Mean

18

Range $0-82$

*Using the Standard Occupational Classification (Office of National Statistics [2000] Standard Occupational Classification 2000. Avallable at: $h$ ttp://www.ons. gov.uk/ons/guide-method/classifications/archived-standard-classifications/standard-occupational-classification-2000/index.html) 
Table 2 delivery of intervention related to stroke severity

\begin{tabular}{|c|c|c|c|c|c|}
\hline & & Minor stroke & Moderate stroke & Moderate/severe stroke & Overall \\
\hline \multirow[t]{3}{*}{ Intervention commenced (days post stroke) } & Mean & 29 & 35 & 33 & 30 \\
\hline & Range & $10-47$ & $16-53$ & $29-37$ & $10-53$ \\
\hline & SD & 11 & 16 & 6 & 11 \\
\hline \multirow[t]{3}{*}{ Number of sessions received } & Mean & 9 & 12 & 11 & 10 \\
\hline & Range & $1-25$ & $1-24$ & $9-13$ & $1-25$ \\
\hline & SD & 6 & 11 & 3 & 7 \\
\hline \multirow[t]{3}{*}{ Duration of intervention (days) } & Mean & 222 & 248 & 240 & 231 \\
\hline & Range & $21-365$ & $48-369$ & $178-302$ & $21-369$ \\
\hline & SD & 109 & 144 & 88 & 112 \\
\hline
\end{tabular}


Figure 1 - Intervention Content

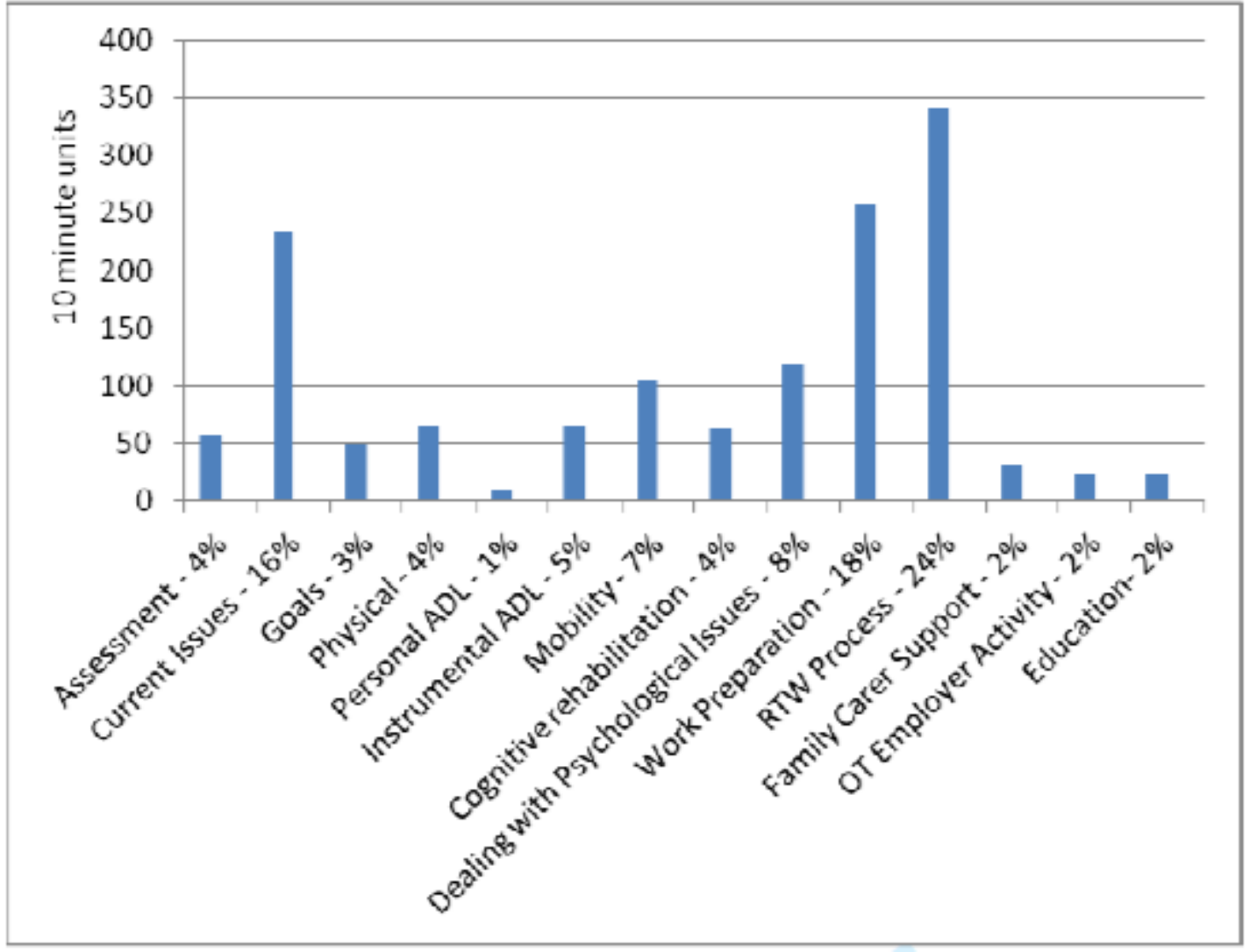

Figure 2 - Liason

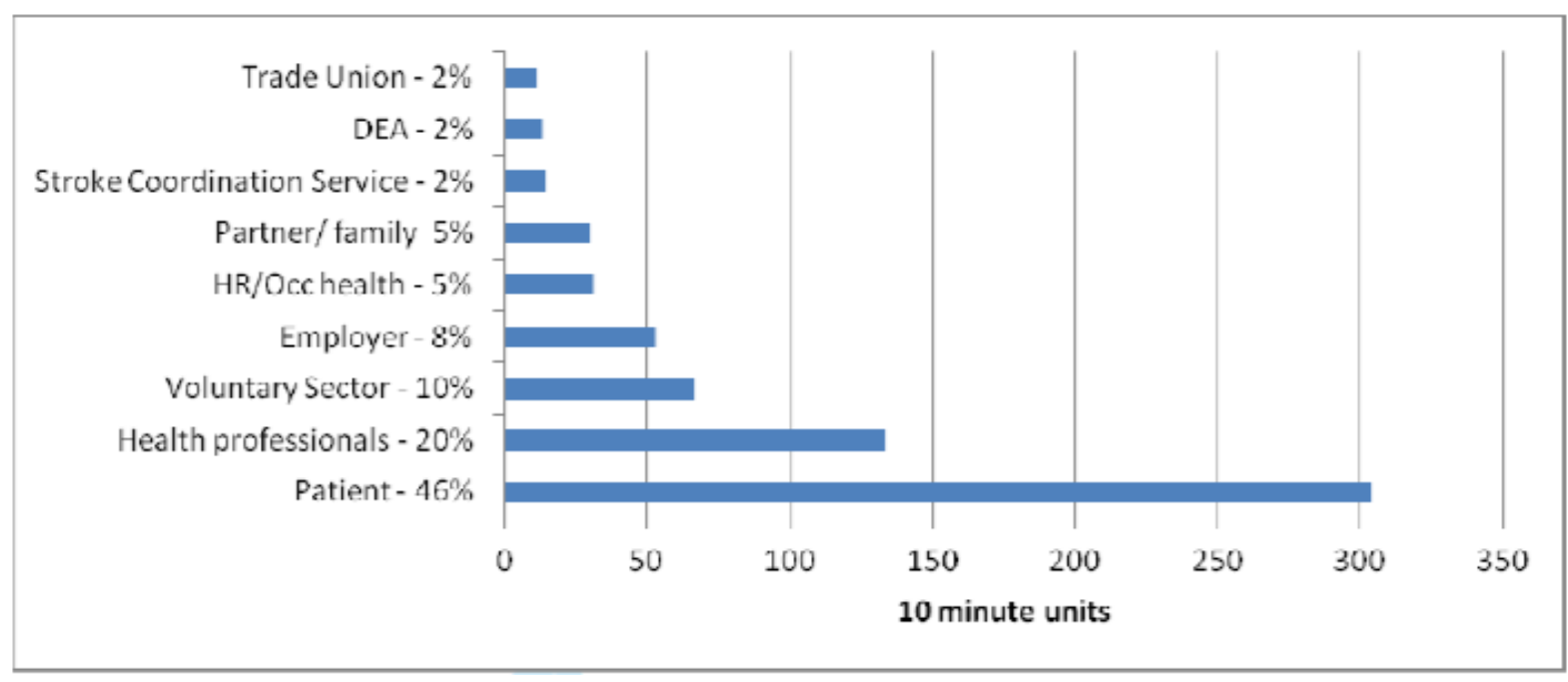


Appendix 1. Occupational Therapy Content Analysis Proforma

\begin{tabular}{|c|c|c|c|}
\hline Participant number: & \multicolumn{2}{|c|}{ Intervention session date: } & Intervention session number: \\
\hline Record in 10 minute units & \multicolumn{2}{|l|}{ Length of session: } & Travel time for session: \\
\hline Where seen & 5. Personal ADL & $\begin{array}{l}\text { 9. Dealing with psychological } \\
\text { issues }\end{array}$ & $\begin{array}{l}\text { 14. Liaison (face-to-face, } \\
\text { letter, phone, email) }\end{array}$ \\
\hline Home & Dressing & Confidence building & Case manager \\
\hline Work & Toileting & Low mood & CBT \\
\hline Job Centre & Bathing/showering & Motivation & Psychologist \\
\hline Other & Other & Anxiety & GP (doctor) \\
\hline 1. Assessment & 6. Instrumental ADL & Behavioural problems & Family \\
\hline Medical history & Making drinks and meals & Dealing with others & Employer \\
\hline Social situation and roles & Housework/laundry & Relaxation techniques & $\begin{array}{l}\text { Human Resources/occupational } \\
\text { health }\end{array}$ \\
\hline Pre-morbid lifestyle & Money/budgeting & Adjustment/re-evaluation* & $\begin{array}{l}\text { Disability Employment Adviser } \\
\text { (DEA) }\end{array}$ \\
\hline Current difficulties & Shopping & 10. Work preparation & Work provider \\
\hline Current abilities & Correspondence & Teach pacing/fatigue management & Carer/partner \\
\hline Family views & Use of phone & Use of routines/time keeping & Patient \\
\hline 2. Current issues & Managing appointments & Discussing work options & Speech and language therapist \\
\hline Medical & Being left alone & Detailed job analysis & Physiotherapist* \\
\hline Social & Leisure activities & $\begin{array}{l}\text { Identify potential problems and } \\
\text { solutions }\end{array}$ & Other \\
\hline Benefits & Sleep issues & Other & 15. OT activity with employer \\
\hline Family & Other & $\begin{array}{l}\text { 11. Return to work (RTW) } \\
\text { process }\end{array}$ & $\begin{array}{l}\text { General advice/education re } \\
\text { stroke }\end{array}$ \\
\hline Work & 7. Mobility & Work site visit* & $\begin{array}{l}\text { Specific advice re individual } \\
\text { and work }\end{array}$ \\
\hline Other & Walking outside home & RTW planning meeting & Information re rehab process \\
\hline 3. Goals & Road safety & Work assessment meeting & $\begin{array}{l}\text { Advice/support re work } \\
\text { assessment }\end{array}$ \\
\hline Identifying problems & Using public transport & Monitoring/grading meeting & Advice/support re graded RTW \\
\hline Identify/set realistic goals & Route finding & Maintenance meeting & Specific advice re any problems \\
\hline Task analysis & Driving & Written info given to employers & $\begin{array}{l}\text { Information about liaison with } \\
\text { statutory services e.g. DEA }\end{array}$ \\
\hline Homework tasks set & Other & Advice/education given & Other \\
\hline Reviewing/modifying goals & 8. Cognitive/executive skills & Statutory issues given & $\begin{array}{l}\text { 16. General education re } \\
\text { stroke or RTW }\end{array}$ \\
\hline 4. Physical & $\begin{array}{l}\text { Educate re cognitive/executive } \\
\text { skills }\end{array}$ & 12. Family/carer support & Patient \\
\hline Transfers & Memory aids/strategies & 13. Administration & Carer \\
\hline Splinting & Attention skills & Note writing & Employer \\
\hline Wheelchairs & Problem solving & Report writing & Written info given \\
\hline Assistive devices and adaptations & Standardized tests & & Other \\
\hline Pain management ${ }^{*}$ & Other & & \\
\hline Visual problems* & & & \\
\hline Communication/speech ${ }^{*}$ & & & \\
\hline Upper limb work* & & & \\
\hline Sensory problems* & & & \\
\hline
\end{tabular}

